\title{
NO counterbalances HO-1 overexpression-induced acceleration of hepatocyte proliferation in mice
}

\author{
Harald Schuett ${ }^{1}$, Christian Eipel ${ }^{1}$, Claudia Maletzki ${ }^{1}$, Michael D Menger ${ }^{2}$ and Brigitte Vollmar $^{1}$
}

The trigger for liver regeneration, including shear stress, has been the subject of ongoing debate. Blood vessel-derived gaseous molecules carbon monoxide (CO) and nitric oxide (NO) regulate vascular tone and play an important role in liver regeneration. In heme oxygenase-1 (HO-1) transgenic mice, it has been shown that CO-mediated impairment of vasorelaxation is an NO-dependent event. We therefore studied liver regeneration in HO-1 overexpressing animals in dependency of NO availability. Mice were subjected to $2 / 3$ hepatectomy and were treated with either cobalt protoporphyrin-IX for induction of CO-liberating HO-1, $N^{\omega}$-nitro-L-arginine methyl ester (L-NAME) for blockade of NO synthase (NOS) or both. Application of molsidomine in L-NAME treated animals served for resubstitution of NO. Vehicletreated animals served as respective control animals. We examined 5-bromo-2'-deoxyuridine incorporation and proliferating cell nuclear antigen expression as well as HO-1 and NOS-2 protein levels. Intrahepatic red blood cell velocity and volumetric blood flow were evaluated by in vivo fluorescence microscopy as indicators for microvascular shear stress. Hepatic regeneration remained unaffected by L-NAME application for NOS blockade. However, NOS blockade in HO-1 induced animals caused increased 5-bromo-2'-deoxyuridine and proliferating cell nuclear antigen measures of liver regeneration. In parallel, these animals revealed increased velocities and volumetric blood flow in the terminal afferent vessels and postsinusoidal venules. These local hemodynamic changes including enhanced hepatocyte proliferation could be reversed by NO liberation via molsidomine. The present findings stress the role of NO to counterbalance vascular tone in HO-1 overexpressing animals for maintenance of adequate perfusion and salutary shear force within the hepatic microvasculature upon liver resection.

Laboratory Investigation (2007) 87, 602-612; doi:10.1038/labinvest.3700548; published online 2 April 2007

KEYWORDS: carbon monoxide; hepatectomy; intravital fluorescence microscopy; proliferation; shear stress

In contrast to most other organs, the liver comprises a unique and remarkable property, ie to regenerate, resulting in a precise reconstitution of the lost tissue mass. ${ }^{1-3}$ Following a two-third hepatectomy, liver cells which normally remain in proliferative quiescence are primed and achieve competence for proliferation. During the subsequent proliferation, the hepatocyte population is expanded. Once the original mass of cells is achieved, regeneration is terminated. ${ }^{1-3}$

The tightly regulated process of liver regeneration is so far not completely understood. Beside numerous cytokine- and growth factor-mediated pathways, ${ }^{1,3}$ hemodynamic alterations, in particular enhanced shear stress upon liver mass resection is one of the main factors contributing to cell proliferation. ${ }^{4-7}$ Within this context, nitric oxide (NO) and carbon monoxide $(\mathrm{CO})$-liberating enzyme systems may play a particular role as both gaseous mediators are released upon enhanced shear stress. ${ }^{7-11}$

It has been reported that these two gaseous transmitter systems are closely linked in that both systems NO producing nitric oxide synthase (NOS) as well as CO releasing heme oxygenase $(\mathrm{HO})$ are capable of modulating each others activity $^{12-14}$ and to some extent even in a reciprocal organ specific manner. ${ }^{15}$ This close association seems to be of particular importance since only the synergistic interaction of $\mathrm{CO}, \mathrm{NO}$ and HO-1 could demonstrate beneficial effects on the cellular level in a model of tumor necrosis factor $\alpha$-induced hepatocyte cell death in mice. ${ }^{16}$

In the context of vasoregulation the interaction is probably even more complex, as there is evidence for a partial agonism of CO for the soluble guanylate cyclase (sGC), which could

\footnotetext{
${ }^{1}$ Institute for Experimental Surgery, University of Rostock, Rostock, Germany and ${ }^{2}$ Institute of Clinical and Experimental Surgery, University of Saarland, Homburg-Saar, Germany

Correspondence: Professor B Vollmar, MD, Institute for Experimental Surgery, University of Rostock, 18055 Rostock, Schillingallee 70, Germany.

E-mail: brigitte.vollmar@med.uni-rostock.de

Received 19 October 2006; revised 22 December 2006; accepted 26 December 2006
} 
cause a suppression of the vasodilatory response to $\mathrm{NO}{ }^{17}$ Moreover, the dual blood supply of the liver is subject of differential regulation by $\mathrm{NO}$ and $\mathrm{CO}^{18}$

So far there are no studies, addressing this intriguing interplay of $\mathrm{NO}$ and $\mathrm{CO}$ in the hepatic microvasculature upon regeneration following partial hepatectomy. We herein demonstrate that cobalt protoporphyrin-IX (CoPP-IX)-induced HO- 1 overexpression combined with inhibition of NOS by $N^{\omega}$-nitro-L-arginine methyl ester (L-NAME) accelerates liver regeneration. This observation is most probably due to the differential modulation of the pre- and intrahepatic vascular system that causes in turn elevated volumetric blood flow and shear stress as trigger for hepatic proliferation. Attenuation of hyperperfusion by additional NO substitution reduced the degree of hepatocyte proliferation to levels of unaffected regenerating livers and thus emphasizing the relevance of basal NOS activity for physiological liver regeneration.

\section{MATERIALS AND METHODS Liver Regeneration Model}

Upon approval by the local government, all experiments were performed in accordance with the German legislation on protection of animals and the National Institute of Health 'Guide for the Care and Use of Laboratory Animals' (Institute of Laboratory Animal Resources, National Research Council; NIH publication 86-23 revised 1985). Male C57BL/ 6J mice (8-10 week old, Charles River Laboratories, Sulzfeld, Germany) were anesthetized by breathing isoflurane (1.5 vol\%) and subjected to a $2 / 3$ hepatectomy. ${ }^{19}$ Animals were placed in supine position and an upper midline incision was followed by retraction of the xyphoid cartilage for adequate exposure of the liver and division of hepatic ligaments. The right upper, the left upper and the left lower liver lobes were resected by placing $4-0$ silk suture ties most proximally to the origin of the lobes. After removal of the tied lobes and irrigation of the abdomen with warm saline, the peritoneum and the skin were closed with running 6-0 and 5-0 sutures, respectively. Subcutaneous $5 \mathrm{ml}$ saline depots served for volume replacement. Animals were allowed to recover from anesthesia and surgery under red warming lamp and held in single cages until the subsequent experiments.

\section{Experimental Groups and Protocol}

For kinetics of HO-1 and NOS-2 expression upon 2/3 hepatectomy, animals without any pretreatment were subjected to $2 / 3$ hepatectomy and killed after $2,4,8,12,18,24,48$ and $96 \mathrm{~h}$ for sampling of liver tissue and subsequent protein extraction ( $n=3$ animals per point in time). In a second set of experiments, animals were subjected to the following treatment in an investigator-blinded fashion: $24 \mathrm{~h}$ before hepatectomy, mice $(n=6)$ were applied CoPP-IX $(15 \mu \mathrm{mol} / \mathrm{kg}$ body weight (bw) intraperitoneal (i.p.)) for HO-1 induction. Control animals received equivalent volumes of the vehicle $8.4 \% \mathrm{NaHCO}_{3} /$ phosphate-buffered saline (PBS) $(n=7)$. To address the role of NOS, both CoPP-IX- $(n=5)$ and vehicle-treated control animals $(n=7)$ additionally received the NOS inhibitor L-NAME $(100 \mathrm{mg} / \mathrm{kg}$ bw, i.p.) $24 \mathrm{~h}$ before and immediately after liver resection. To verify the role of NOS blockade together with concomitant HO-1 overexpression on liver regeneration and hepatic microcirculation animals were treated with molsidomine $(10 \mathrm{mg} / \mathrm{kg}$ bw, i.p.) $24 \mathrm{~h}$ before and immediately after liver resection in addition to CoPP-IX and L-NAME $(n=6)$. Molsidomine is enzymatically converted in the liver to yield the active metabolite SIN-1 which consecutively releases NO. ${ }^{20,21}$ For a condensed survey of the experimental schedule and the number of animals used in each subset as well as the description of the respective groups used in this study see Figure 1 and Table 1.

The HO-1 inductor CoPP-IX was dissolved in $\mathrm{NaHCO}_{3} /$ PBS to achieve a final concentration of $1.5 \mu \mathrm{mol} / \mathrm{ml}$. L-NAME (Axxora Life Sciences, Grünberg, Germany) and molsidomine (Sigma-Aldrich Chemie GmbH, Munich, Germany) were dissolved in sterile saline. All solutions were freshly prepared at the day of the experiment. Dose and application mode of drugs were chosen in accordance to previously published work of our and other groups. ${ }^{22-25}$

At $48 \mathrm{~h}$ after liver resection, during maximum of DNA synthesis, ${ }^{26}$ animals were anesthetized with ketamine/xylazine $(90 / 25 \mathrm{mg} / \mathrm{kg}$ bw, ip) for retrobulbar sampling of blood. In addition, liver tissue was excised, weighed and harvested for subsequent analysis.

Being aware that liver weight is influenced by various extrinsic and intrinsic factors that are often unrelated to hepatic regeneration, we assessed expression of proliferating cell nuclear antigen (PCNA) by immunohistochemistry, which has been described to serve as an accurate and reliable marker to quantitatively assess hepatic regeneration. ${ }^{27}$ As PCNA may only reflect regeneration on a cell-to-cell basis, we additionally used 5-bromo-2'-deoxyuridine (BrdU, Sigma-Aldrich) incorporation to study DNA synthesis upon liver resection. ${ }^{28}$ For this purpose, $\mathrm{BrdU}(50 \mathrm{mg} / \mathrm{kg}$ bw, i.p.) was dissolved in PBS to achieve a final concentration of $5 \mathrm{mg} / \mathrm{ml}$ and applied intraperitoneally $1 \mathrm{~h}$ before sacrifice. ${ }^{29}$

\section{Western Blot Analysis of Liver Tissue}

Complementary to the conventional measurement of plasma nitrate/nitrite as metabolites of NO, we determined the direct effect of NO in liver tissue. Formation of free and proteinbound 3-nitrotyrosine (3-NT) adducts was used as a probe for $\mathrm{NO}$ and its reactive nitrogen species mediated tissue interference. ${ }^{30}$ Thus, detection of these adducts could be utilized to determine the amount of NO applied to the liver in the experimental groups.

For whole protein extracts and Western blot analysis of HO-1, NOS-2, and 3-NT, liver tissue was homogenized in lysis buffer (10 mM Tris, pH 7.5, $10 \mathrm{mM} \mathrm{NaCl}, 0.1 \mathrm{mM}$ EDTA, $0.5 \%$ Triton-X 100, $0.02 \% \mathrm{NaN}_{3}$, and $0.2 \mathrm{mM}$ phenylmethylsulfonyl fluoride), incubated for $30 \mathrm{~min}$ on ice, and centrifuged for $15 \mathrm{~min}$ at $10000 \mathrm{~g}$. Before use, all buffers 

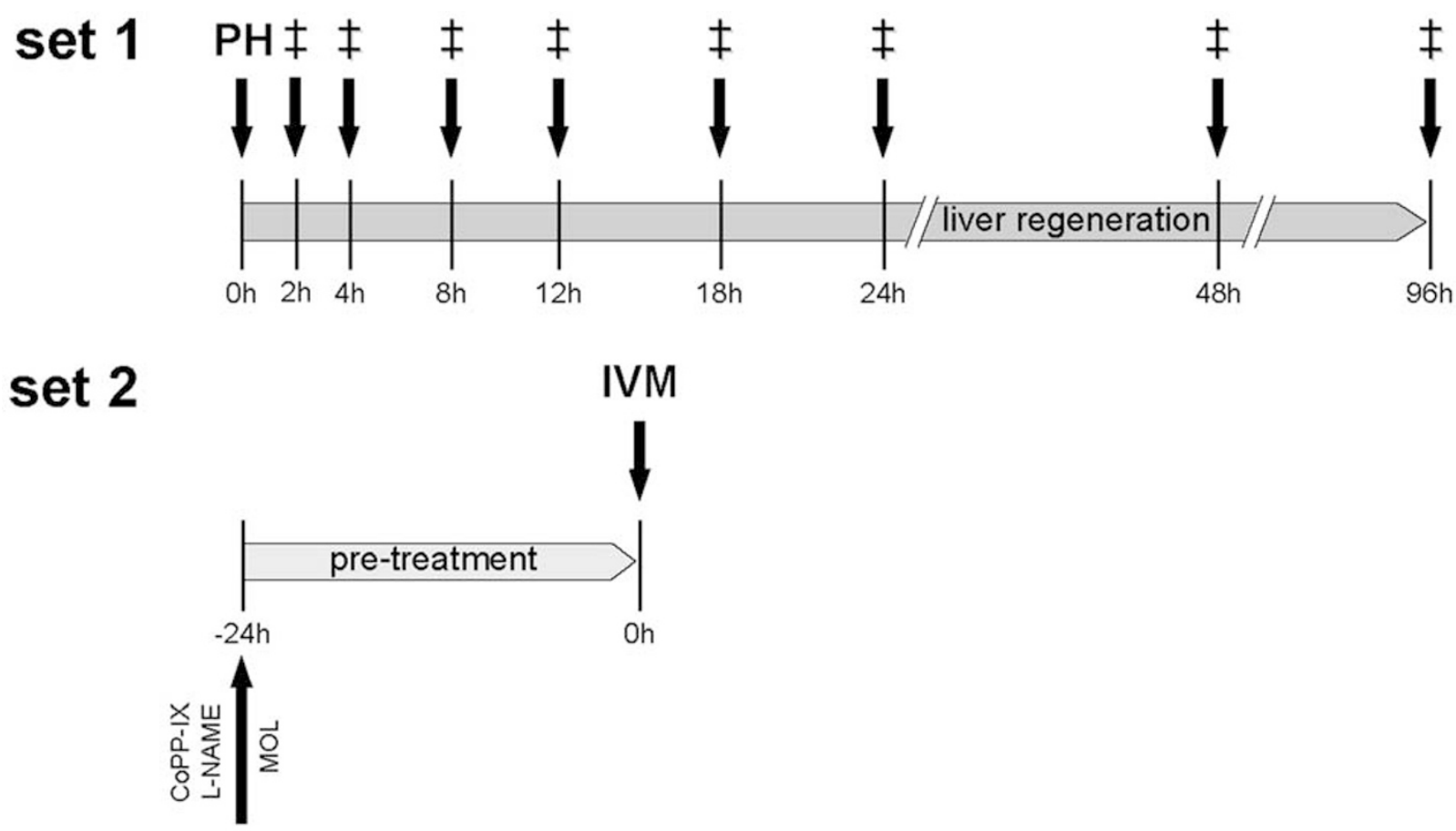

set 3

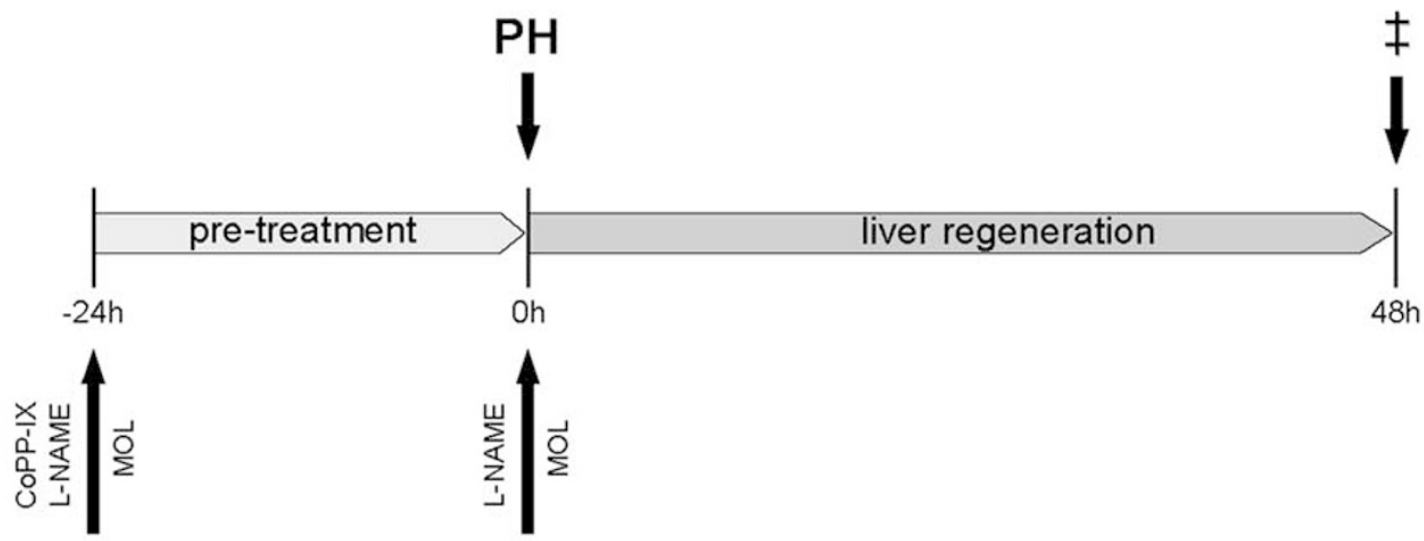

Figure 1 Experiments were performed in three seperate sets of animals: In set 1 animals without any pretreatment were subjected to $2 / 3$ hepatectomy (PH) and sacrificed ( $\ddagger$ ) at the indicated points in time for sampling of liver tissue and subsequent analysis. In set 2 intravital fluorescence microscopy (IVM) was performed to assess hepatic microhemodynamics after respective pretreatment at the point in time which equals to the point in time of resection in set 3. In set 3 animals were subjected to PH after the respective pre-treatment and sacrificed at $48 \mathrm{~h}$ post-PH for sampling of liver tissue. For further information, see Materials and methods as well as Table 1.

received a protease inhibitor cocktail $(1: 100, \mathrm{v} / \mathrm{v}$; SigmaAldrich). Protein concentrations were determined using the bicinchoninic acid protein assay (Pierce Biotechnology, Bonn, Germany) with bovine serum albumin as standard.

Equal amounts of protein (HO-1: $20 \mu \mathrm{g}$, NOS-2: $20 \mu \mathrm{g}$, 3-NT: $40 \mu \mathrm{g}$ ) were separated discontinuously on sodium dodecyl sulfate polyacrylamide gels (12\%) and transferred to a polyvinyldifluoride membrane (Immobilon-P, Millipore, Eschborn, Germany). After blockade of non-specific binding sites, membranes were incubated for $2 \mathrm{~h}$ at room temperature with rabbit-polyclonal anti-HO-1 (1:5000, Stressgen Biotech, San Diego, CA, USA), rabbit-polyclonal anti-NOS-2 (1:2000, Calbiochem, San Diego, CA, USA) and mouse-monoclonal
anti-3-NT (1:1000, Santa Cruz Biotechnology, Heidelberg, Germany), followed by a peroxidase-conjugated goat antirabbit immunoglobulin G (IgG) (HO-1 1:60 000, NOS-2 1:20 000; Cell Signalling Technology, Frankfurt, Germany) and a peroxidase-conjugated rabbit anti-mouse IgG respectively (3-NT 1:5 000; Sigma-Aldrich) as secondary antibodies. Protein expression was visualized by means of luminol enhanced chemiluminescence (ECL plus; Amersham Pharmacia Biotech, Freiburg, Germany) and exposure of the membrane to a blue light sensitive autoradiography film (Kodak BioMax Light Film, Kodak-Industrie, Chalon-sur-Saone, France). Signals were densitometrically assessed (Gel-Dokumentationssystem TotalLab, Nonlinear Dynamics, New Castle upon 
Table 1 Experimental groups and number of animals per group

\begin{tabular}{|c|c|c|c|c|c|}
\hline Groups & CoPP-IX & L-NAME & $\mathrm{MOL}$ & $n(\mathrm{PH})$ & $n$ (IVM) \\
\hline Control & - & - & - & 7 & 6 \\
\hline Control/L-NAME & - & + & - & 7 & 6 \\
\hline CoPP-IX/L-NAME/MOL & + & + & + & 6 & 5 \\
\hline
\end{tabular}

Experiments were performed in separate sets of animals, to assess hepatic microhemodynamics by intravital fluorescence microscopy (IVM) at the point in time of resection and also to assess additional animals which underwent $2 / 3$ hepatectomy ( $\mathrm{PH}$ ) for subsequent sampling of blood and liver tissue at $48 \mathrm{~h}$ post hepatectomy. For further information, please see Materials and methods as well as Figure 1.

Tyne, UK) and normalized to the $\beta$-actin signals as loading controls (mouse monoclonal anti- $\beta$-actin antibody, 1:20 000; Sigma-Aldrich).

\section{Histology and Immunohistochemistry of Liver Tissue}

Liver tissue was fixed in 4\% phosphate buffered formalin for 2-3 days and embedded in paraffin. From the paraffinembedded tissue blocks, $4 \mu \mathrm{m}$ sections were cut and stained with hematoxylin-eosin for histological analysis. For immunohistochemical demonstration of HO-1, PCNA and BrdU, sections collected on poly-L-lysine-coated glass slides were treated by microwave for antigen unmasking. Rabbit polyclonal anti-HO-1 (1:2000; Stressgen Biotech), rabbit polyclonal anti-PCNA (1:50; Santa Cruz Biotechnology) and mouse monoclonal anti-BrdU (1:50; Dako Cytomation, Hamburg, Germany) were used as primary antibodies and incubated for $18 \mathrm{~h}$ at $4{ }^{\circ} \mathrm{C}$. After equilibrating to room temperature, sections were incubated with horseradish peroxidase-conjugated goat anti-rabbit IgG (HO-1 1:100), alkaline phosphatase-conjugated goat anti-rabbit IgG (PCNA; 1:20) or horseradish peroxidase-conjugated goat anti-mouse IgG (BrdU, 1:100) for $30 \mathrm{~min}$ (all from Dako Cytomation). 3,3'diaminobenzidine (HO-1 and BrdU) or fuchsin (PCNA) were used as chromogens. Then the sections were counterstained with hemalaun and examined by light microscopy (Axioskop 40, Zeiss, Göttingen, Germany). PCNA- and BrdU-positive nuclei as well as $\mathrm{HO}$-1-positive hepatocytes were counted within 40 consecutive high power fields $(\times 40$ objective, numerical aperture 0.65$)$ and are given as cells $/ \mathrm{mm}^{2}$.

\section{Intravital Fluorescence Microscopy}

To analyze the effect of concomitant HO-1 induction (CoPPIX) and NOS blockade (L-NAME) as well as the effect of restoration of the NO balance (molsidomine) in comparison to control animals on hepatic microcirculation, in a third study set pretreated animals were studied at the moment of resection ( $n=5-7$ per group; for a condensed survey of the number of animals used in each subset as well as the description of the respective groups used in this set see Figure 1 and Table 1). For this purpose, spontaneously breathing ketamine/xylazine $(90 / 25 \mathrm{mg} / \mathrm{kg}$ bw, i.p.) anesthetized animals were placed on their left side on a heating pad for maintenance of body temperature at $36-37^{\circ} \mathrm{C}$. The left liver lobe was exteriorized and covered with a glass slide for microscopy and assessment of microhemodynamics within the afferent terminal vessels, the sinusoids and outflowing postsinusoidal venules.

Using a fluorescence microscope equipped with a $100 \mathrm{~W}$ mercury lamp (Axiotech vario, Zeiss, Jena, Germany) and a filter for blue light epi-illumination (excitation/emission wavelength: $450-490 \mathrm{~nm} />520 \mathrm{~nm}$ ), microscopic images were taken by a water immersion objective $(\times 20 /$ numerical aperture $0.50 \mathrm{~W}$, Zeiss), recorded by a CCD video camera (FK 6990A-IQ, Pieper, Berlin, Germany) and transferred to a video system (S-VHS Panasonic AG 7350-E, Matsushita, Tokyo, Japan).

\section{Quantitative Video Analysis}

For contrast enhancement, the plasma marker fluorescein isothiocyanate-dextran $(5 \%, 0.1 \mathrm{ml} / 100 \mathrm{~g}$ bw; Sigma-Aldrich) was used to assess red blood cell velocity $\left(\mathrm{v}_{\mathrm{RBC}}\right)$ within the individual microvessels, that is, afferent terminal vessels (terminal hepatic arterioles and terminal portal venules), hepatic sinusoids, and postsinusoidal venules, as described previously. ${ }^{31}$ Volumetric blood flow (VQ) in the individual microvessels was estimated from $\mathrm{v}_{\mathrm{RBC}}$ and microvascular cross-sectional area $\left(\pi r^{2}\right)$ according to the equation of Gross and Aroesty, ${ }^{32}$ that is, $\mathrm{VQ}=\mathrm{v}_{\mathrm{RBC}} \pi r^{2}$. Though the equation is very simplistic inasmuch as a cylindrical shape of the respective microvessel is assumed and values may not accurately reflect the actual flow, they allow assessment of relative differences between groups. Shear stress $(\tau)$ applied to the hepatic microvasculature was calculated according to the following formula: $\tau=4 \eta \mathrm{VQ} / \pi r^{3}$, where $r$ is the radius and $\eta$ the blood viscosity. ${ }^{33,34}$

Quantification of microhemodynamic parameters was performed offline by frame-to-frame analysis of the 


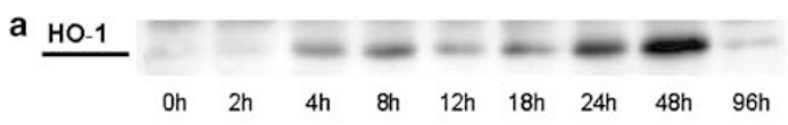

\section{B-actin}

b

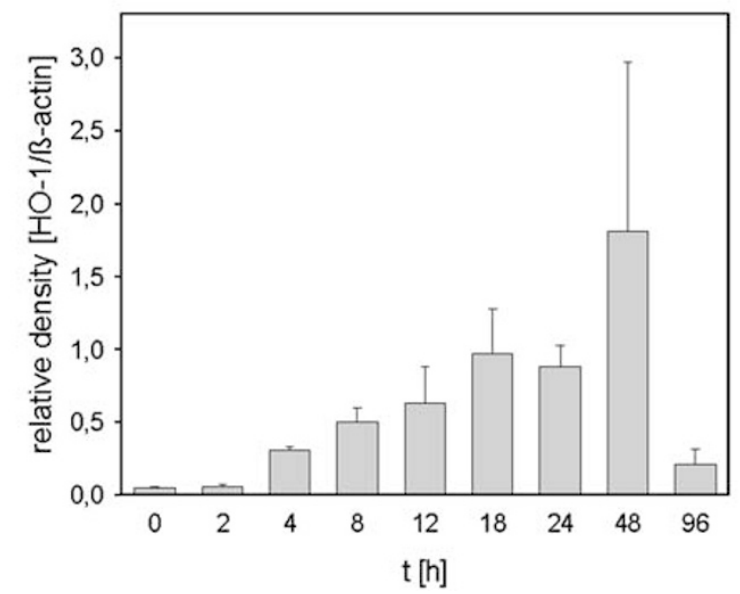

C NOS-2

B-actin Oh $\quad 2 \mathrm{~h} \quad 4 \mathrm{~h} \quad 8 \mathrm{~h} \quad 12 \mathrm{~h} \quad 18 \mathrm{~h} \quad 24 \mathrm{~h} \quad 48 \mathrm{~h} \quad 96 \mathrm{~h}$

d

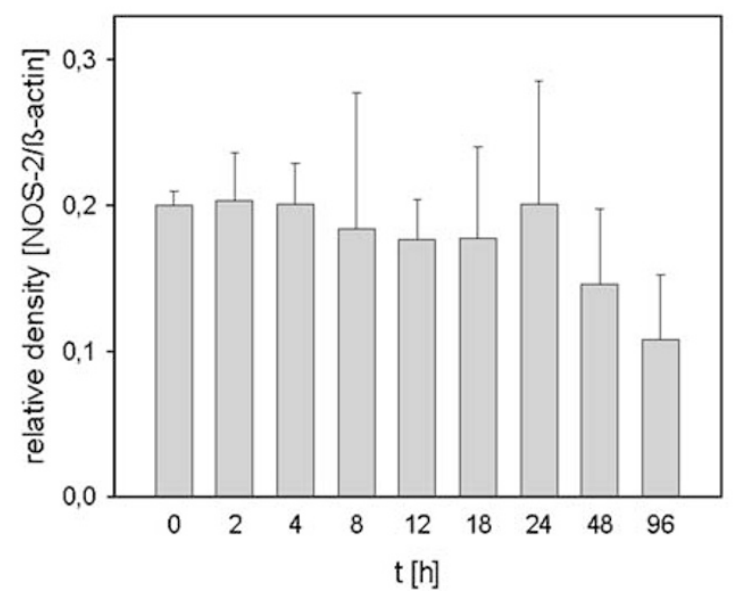

Figure 2 Representative Western blots and quantitative densitometric analysis of HO-1 (a and b) and NOS-2 (c and d) in liver tissue of animals over $2 \mathrm{~h}$ to $96 \mathrm{~h}$ after $2 / 3$ hepatectomy without any pretreatment ( $n=3$ per point in time). Values are means \pm s.e.m.

videotaped images using a computer-assisted image analysis system (Cap-Image; Zeintl, Heidelberg, Germany). In each animal five sinusoidal observation fields were recorded. Per observation field, red blood cell velocity and diameter in midzonal regions of the sinusoidal pathway (classification according to Rappaport ${ }^{35}$ ) were assessed in a total of 5-10 individual sinusoids. A total of 5-10 terminal hepatic arterial and portal venous vessels and 5-10 postsinusoidal venules per animal each were recorded and analyzed for red blood cell velocity and diameter. Mean values for red blood cell velocity and diameter (3-5 measurements per individual microvessel with subsequent calculation of mean values) were used for calculation of volumetric blood flow and shear stress for each individual microvascular segment (5-10 terminal hepatic arteriolar, terminal portal venular, sinusoidal and postsinuoidal vessels per animal). Subsequently, these data were averaged for each individual animal and there upon the data of all animals per group were summarized as mean \pm s.e.m.

\section{Statistical Analysis}

All experiments were performed in an investigator-blinded fashion. Data are expressed as means \pm s.e.m. After proving the assumption of normality and equal variance across groups, differences between groups were assessed using analysis of variance followed by the appropriate post hoc comparison test. Statistical significance was set at $P<0.05$. Statistics were performed using the software package SigmaStat (Jandel Corporation, San Rafael, CA, USA).

\section{RESULTS \\ Effect of Liver Resection on HO-1 Expression and Its Modulation by CoPP-IX}

As revealed by Western blot analysis, regeneration of liver tissue upon 2/3 resection caused a marked increase of HO-1 expression over time with an apparent maximum at $48 \mathrm{~h}$ after hepatectomy when compared with that of normal quiescent liver tissue (Figure $2 \mathrm{a}$ and $\mathrm{b}$ ). In contrast, there was no rise in NOS-2 protein expression over the time course of $96 \mathrm{~h}$ after hepatectomy (Figure $2 \mathrm{c}$ and d). CoPP-IX pretreated animals which were subjected to hepatectomy showed a $\sim 5$-fold increase of HO-1 protein levels in liver tissue (Figure 3a and c). In line with these densitometric data, histochemistry for HO-1 expression revealed marked immunoreactivity of hepatocytes upon liver regeneration. The number of HO-1 positive cells was found to be even 2.5-fold higher by additional HO-1 induction with CoPP-IX in comparison to vehicle-treated controls (Figure $3 \mathrm{~b}$ and $\mathrm{d}$ ).

\section{Effect of L-NAME and Molsidomine on Formation of 3-NT Adducts}

Though not statistically significant, there was at least a distinct attenuation of 3-NT adducts in animals treated with L-NAME, while administration of the NO-donor molsidomine in addition to L-NAME resulted in a normalized 3-NT level indicating a recovery of the NO balance (Figure $4 \mathrm{a}$ and b).

\section{Effect of HO-1 and NOS Modulation on Hepatic Regeneration}

Immunohistochemical analysis of PCNA protein and BrdU incorporation were performed for reliable assessment of liver 
a
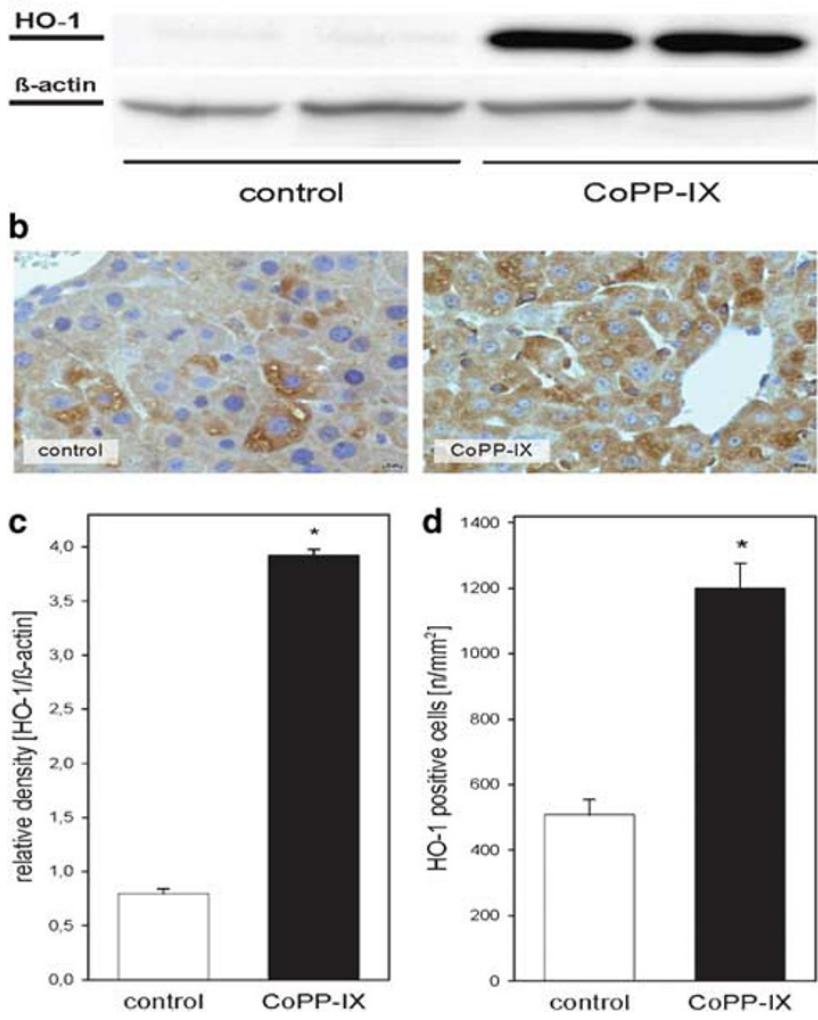

Figure 3 Western blot analysis (a) and quantitative densitometric analysis (c) of HO-1 protein levels as well as representative images $(\mathbf{b}$; original magnification $\times 400$ ) and quantitative analysis (d) of HO-1 immunohistochemistry (cytoplasmatic staining with $3,3^{\prime}$-diaminobenzidine as chromogen in brown), given as $\mathrm{HO}-1$ positive cells in regenerating livers. Mice were treated with CoPP-IX for HO-1 induction (black bars) or with equivalent volumes of the vehicle $\mathrm{NaHCO}_{3} / \mathrm{PBS} 24 \mathrm{~h}$ before hepatectomy (white bars). Liver tissue was harvested $48 \mathrm{~h}$ after hepatectomy. Values are means \pm s.e.m.; $5-8$ animals per group; ${ }^{*} P<0.05$ vs control.

regeneration (Figure $5 \mathrm{a}-\mathrm{d}$ ). Tissue sections revealed significantly increased numbers of PCNA and BrdU positive cells in HO-1-induced (CoPP-IX) animals with concomitant NOS blockade in contrast to those without L-NAME treatment. To clarify the effect of additional NOS blockade on liver regeneration, NO balance was recovered by molsidomine administration. Thereupon, animals with CoPP-IX, L-NAME and molsidomine treatment exhibited PCNA and BrdU immunostaining comparable to those in controls (Figure 5a-d).

\section{Effect of HO-1 and NOS Modulation on Hepatic Microcirculation}

Quantitative analysis of the hepatic microcirculation in HO-1-induced animals with L-NAME application revealed increased values of $\mathrm{v}_{\mathrm{RBC}}$ and the size of diameters in terminal afferent vessels, sinusoids and postsinusoidal venules of livers at the point in time of resection when compared with the corresponding values in animals of the other groups (Table 2). Moreover, in these animals values of volumetric blood a

3-NT
B-actin
\begin{tabular}{|l|c|c|c|c|c|}
\hline COPP-IX & - & - & + & + & + \\
\hline L-NAME & - & + & - & + & + \\
\hline MOL & - & - & - & - & + \\
\hline
\end{tabular}

b

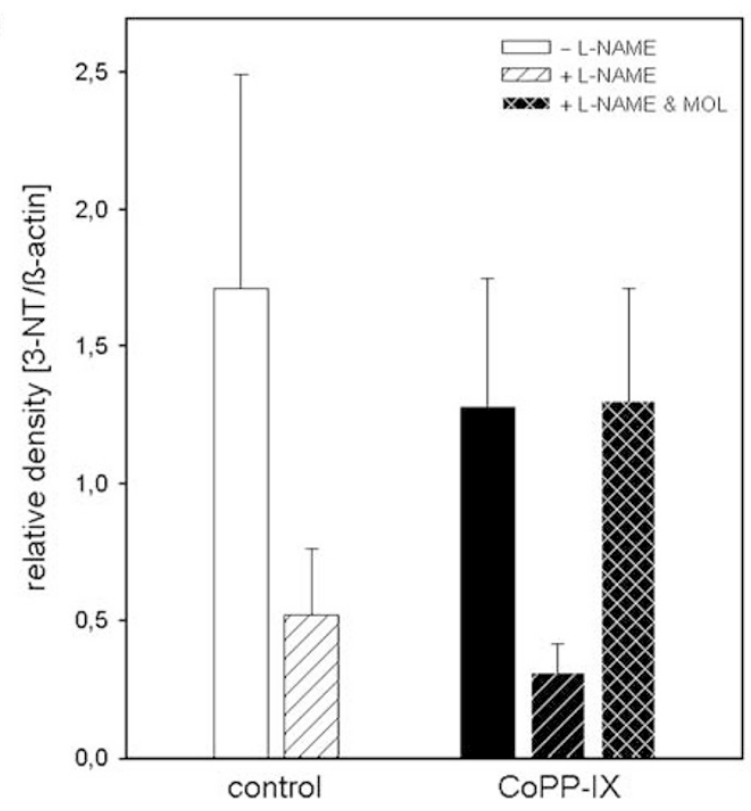

Figure 4 Representative Western blot (a) and quantitative densitometric analysis (b) of 3-NT adduct formation. Mice were treated with CoPP-IX for $\mathrm{HO}-1$ induction (black bars) or with equivalent volumes of the vehicle $\mathrm{NaHCO}_{3} / \mathrm{PBS} 24 \mathrm{~h}$ before hepatectomy (white bars). For NOS-blockade additional groups were treated with L-NAME $24 \mathrm{~h}$ before and immediately after hepatectomy (hatched bars). To clarify the effect of NOS blockade (L-NAME) with concomitant HO-1 overexpression (CoPP-IX), recovery of NO balance was achieved by administration of molsidomine $(\mathrm{MOL}, 10 \mathrm{mg} / \mathrm{kg}$ bw, i.p.) $24 \mathrm{~h}$ before and immediately after liver resection (chequered bars). Liver tissue was harvested $48 \mathrm{~h}$ after hepatectomy. Values are means \pm s.e.m.; 5-8 animals per group. Although the results clearly reflect reduced NO availability upon L-NAME as well as reconstitution of NO availability by molsidomine, statistical analysis using ANOVA and post hoc pairwise comparison did not reveal significant differences.

flow, derived from the distinct parameters mentioned above $\left(\mathrm{VQ}=\mathrm{v}_{\mathrm{RBC}} \pi r^{2}\right)$, in most of the microvascular segments of the liver significantly exceeded those found in livers of control animals and in HO-1-overexpressing animals with functional NOS (Figure 6a-c). Assessment of shear stress, which is closely associated with volumetric blood flow $\left(\tau=4 \eta \mathrm{VQ} / \pi r^{3}\right)$, exhibited a comparable pattern of differences between the groups with notably increased values in animals with HO-1 induction and concomitant NOS blockade (Figure $7 \mathrm{a}-\mathrm{c}$ ). Interestingly the additional treatment of these animals with molsidomine to recover NO balance led 
a

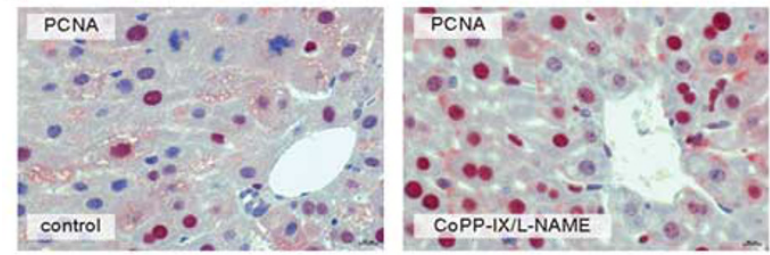

b

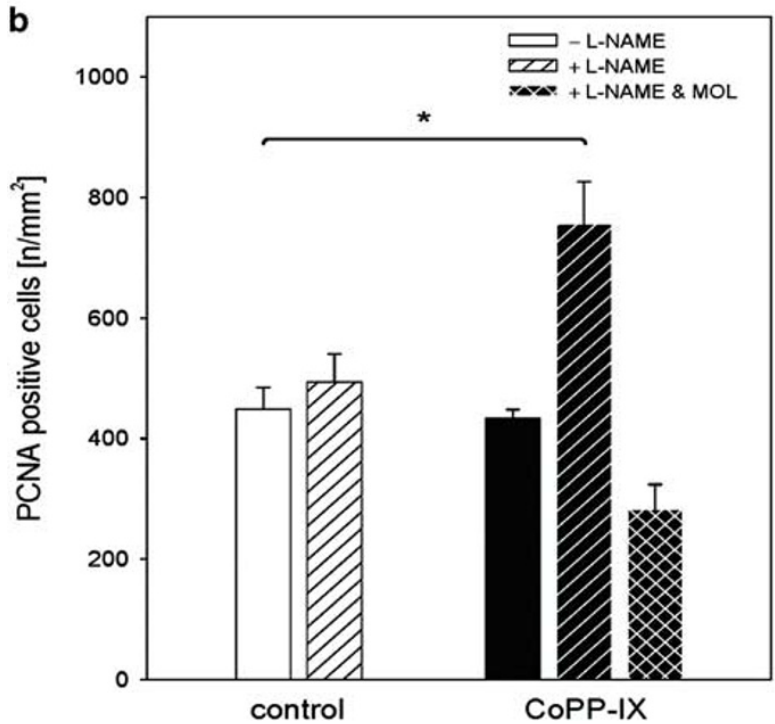

C
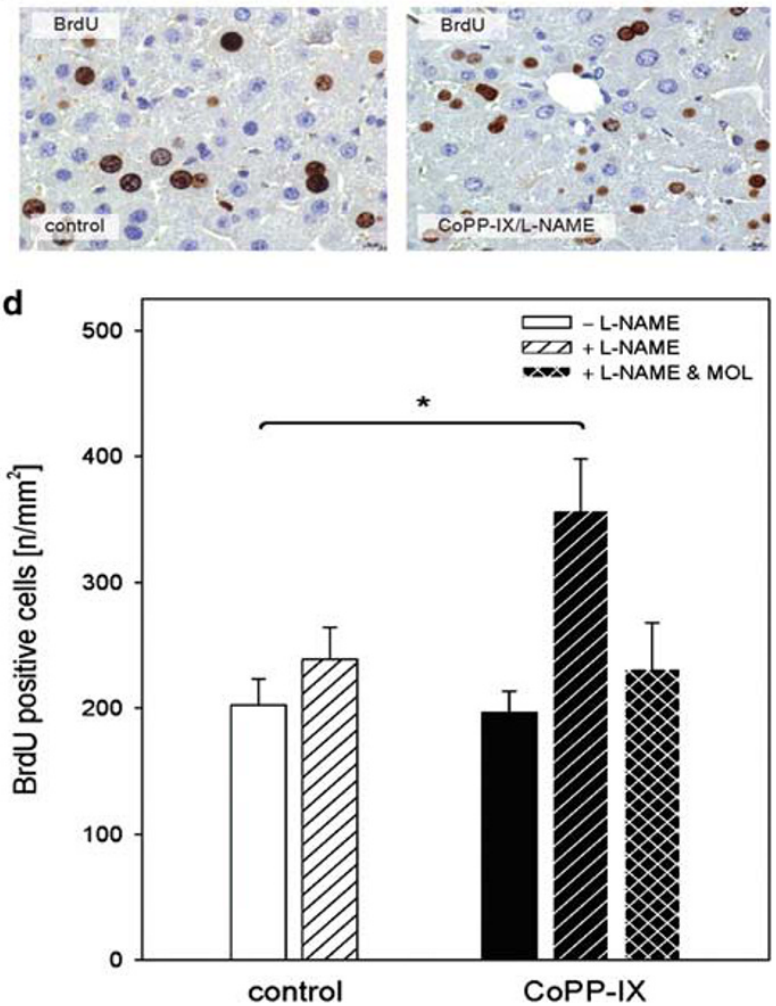

Figure 5 Representative images (a and c; original magnification $\times 400$ ) and quantitative analysis (b and $\mathbf{d}$ ) of PCNA (nuclear staining with fuchsin as chromogen in red) and BrdU immunohistochemistry (nuclear staining with 3,3'-diaminobenzidine as chromogen in brown), given as number of PCNA or BrdU-positive cells $/ \mathrm{mm}^{2}$ in regenerating livers. Mice were treated with CoPP-IX for HO-1 induction (black bars) or with equivalent volumes of the vehicle $\mathrm{NaHCO}_{3} / \mathrm{PBS} 24 \mathrm{~h}$ before hepatectomy (white bars). For NOS blockade additional groups were treated with L-NAME $24 \mathrm{~h}$ before and immediately after hepatectomy (hatched bars). To clarify the effect of NOS blockade (L-NAME) with concomitant HO-1 overexpression (CoPP-IX) on the liver regeneration, recovery of NO balance was achieved by administration of molsidomine ( $\mathrm{MOL}, 10 \mathrm{mg} / \mathrm{kg}$ bw, i.p.) $24 \mathrm{~h}$ before and immediately after liver resection (chequered bars). Liver tissue was harvested $48 \mathrm{~h}$ after hepatectomy. Values are means \pm s.e.m.; $5-8$ animals per group; ${ }^{\star} P<0.05$ vs control.

to a decline of all microhemodynamic parameters towards control values, comparable to the changes observed for hepatocyte proliferation (Figures 5-7).

\section{DISCUSSION}

Herein, we communicate the following major findings: (i) hepatocyte regeneration upon liver resection was associated with increased levels of HO-1, but not NOS-2 protein; and (ii) inhibition of NO synthesis by L-NAME did not influence regeneration parameters, as assessed by PCNA and BrdU immunostaining at $48 \mathrm{~h}$ after resection (point in time of maximal DNA synthesis). However, if HO-1 is overexpressed, NO seems to be mandatory to keep up the appropriate vascular tone, as L-NAME treatment in CoPP-IX-exposed animals caused intrahepatic hyperperfusion which in turn caused elevation in shear stress consecutively triggering hepatic proliferation. This view is supported by the fact that attenuation of this hyperperfusion-induced acceleration of hepatocyte proliferation to levels found in untreated regenerating livers could be achieved by resubstitution of NO using molsidomine.
$\mathrm{CO}$ as a product of the HO-1 pathway is known to upregulate the sGC activity with release of cyclic guanosine monophosphate and therefore exhibits similar physiological properties to NO, such as smooth muscle relaxation and inhibition of platelet aggregation. ${ }^{36-38}$ As the liver represents one of the most abundant sources of $\mathrm{HO}$, constitutive levels of $\mathrm{CO}$ are considered to be necessary for maintenance of its low vascular resistance. ${ }^{39,40}$ Concomitantly, the absence of both constitutive and inducible NOS in liver tissue implies the negligible role of $\mathrm{NO}$ in tonus control of the hepatic microvasculature, at least under physiological conditions, ${ }^{39}$ though $\mathrm{CO}$ seems to be weaker in stimulation of sGC than $\mathrm{NO}^{36,41}$

Both gaseous mediators have been shown to be released in a shear-stress dependent manner. ${ }^{11,33}$ Shear stress, being proportional to the blood flow and the inverse of the cube of the vessel radius, ${ }^{33,42}$ characteristically appears upon the increase in the blood flow-to-liver mass ratio during liver resection and has been noted as a possible trigger in the early stages of liver regeneration. ${ }^{43}$ In perfused livers isolated from normal rats, it has been shown that NO was released by norepinephrine-induced vasoconstriction at constant flow 
Table $2 \mathrm{~V}_{\mathrm{RBC}}[\mu \mathrm{m} / \mathrm{s}]$ and diameters [ $\left.\mu \mathrm{m}\right]$ of hepatic terminal afferent vessels, sinusoids and postsinusoidal venules in mice which underwent HO-1 induction by COPP-IX with and without NOS blockade by L-NAME as well as recovery of NO balance by administration of molsidomine (MOL)

Terminal afferent vessels

Sinusoids

Postsinusoidal venules

$v_{R B C}[\mu \mathrm{m} / \mathrm{s}]$

$\begin{array}{ll}\text { Control } & 265 \pm 16 \\ \text { Control/L-NAME } & 252 \pm 31 \\ \text { CoPP-IX } & 278 \pm 20 \\ \text { COPP-IX/L-NAME } & 356 \pm 38 \\ \text { CoPP-IX/L-NAME \& MOL } & 248 \pm 30\end{array}$

$168 \pm 9$
$202 \pm 27$
$168 \pm 16$
$222 \pm 36$
$176 \pm 14$

$377 \pm 51$

$390 \pm 40$

$352 \pm 40$

$548 \pm 65$

$340 \pm 42$

Diameter $[\mu \mathrm{m}]$

Control

Control/L-NAME

COPP-IX

COPP-IX/L-NAME

COPP-IX/L-NAME \& MOL
$26.6 \pm 1.9$
$22.9 \pm 1.4$
$27.2 \pm 1.4$
$28.3 \pm 1.4$
$24.8 \pm 1.0$

$10.2 \pm 0.4$

$27.8 \pm 2.5$

$10.4 \pm 0.2$

$23.0 \pm 2.4$

$10.1 \pm 0.4$

$28.7 \pm 2.0$

$11.0 \pm 0.2$

$31.1 \pm 2.2$

$10.9 \pm 0.3$

Values are given as means \pm s.e.m. For further information, please see Materials and methods.
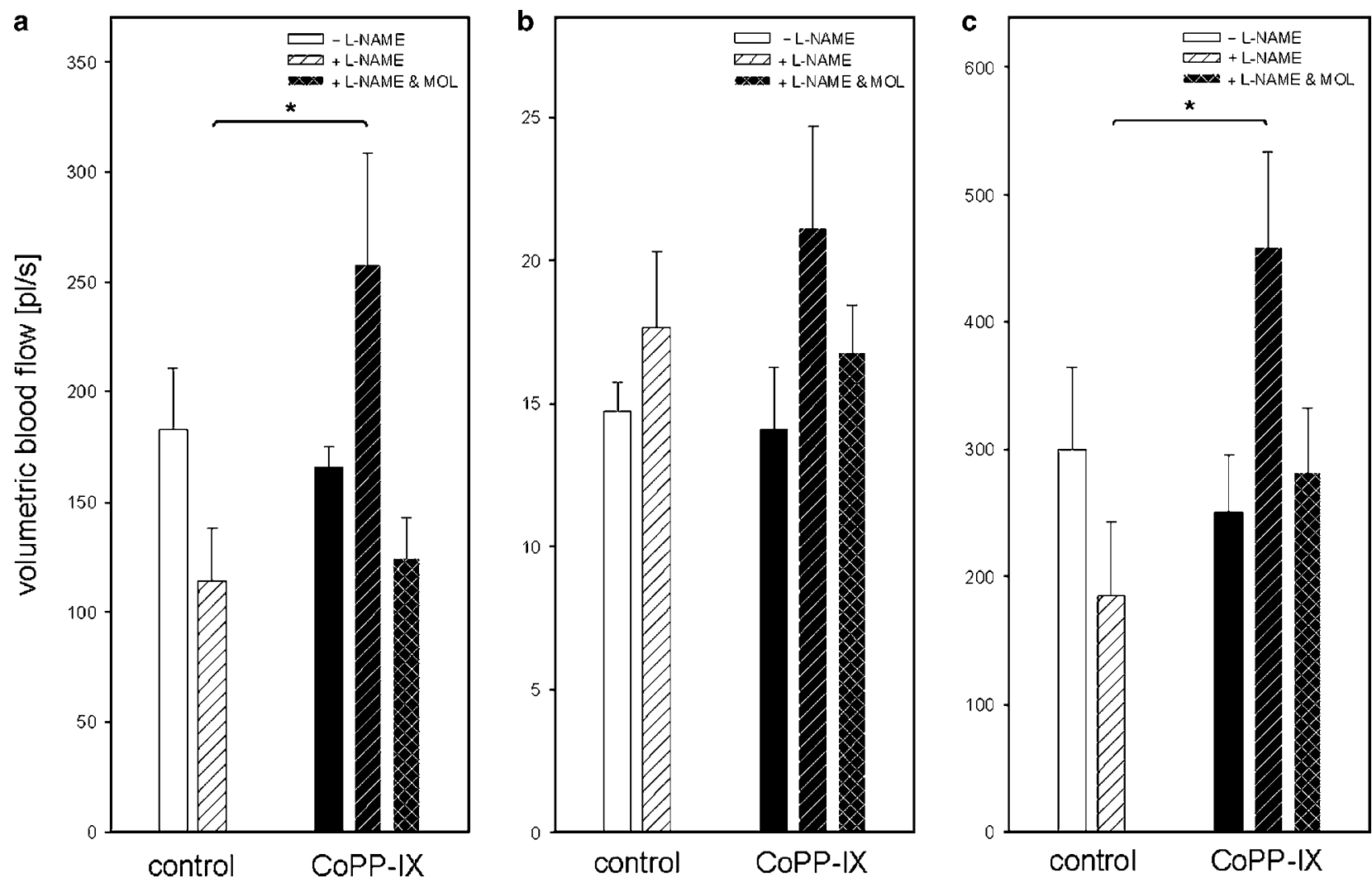

Figure 6 Volumetric blood flow in terminal afferent vessels (a), sinusoids (b) and postsinusoidal venules (c) of livers, as assessed by in vivo microscopy. Mice were either treated with CoPP-IX for $\mathrm{HO}-1$ induction (black bars) or with equivalent volumes of the vehicle $\mathrm{NaHCO}_{3} / \mathrm{PBS}$ (white bars) $24 \mathrm{~h}$ before microscopy. For NOS blockade additional groups were treated with L-NAME $24 \mathrm{~h}$ before microscopy (hatched bars). To clarify the effect of NOS blockade (L-NAME) with concomitant HO-1 overexpression (CoPP-IX) on the liver microcirculation, recovery of NO balance was achieved by administration of molsidomine (MOL, $10 \mathrm{mg} / \mathrm{kg}$ bw, i.p.) $24 \mathrm{~h}$ before and immediately after liver resection (chequered bars). Values are means \pm s.e.m.; $5-7$ animals per group; ${ }^{*}<<0.05$ vs control/ L-NAME. 

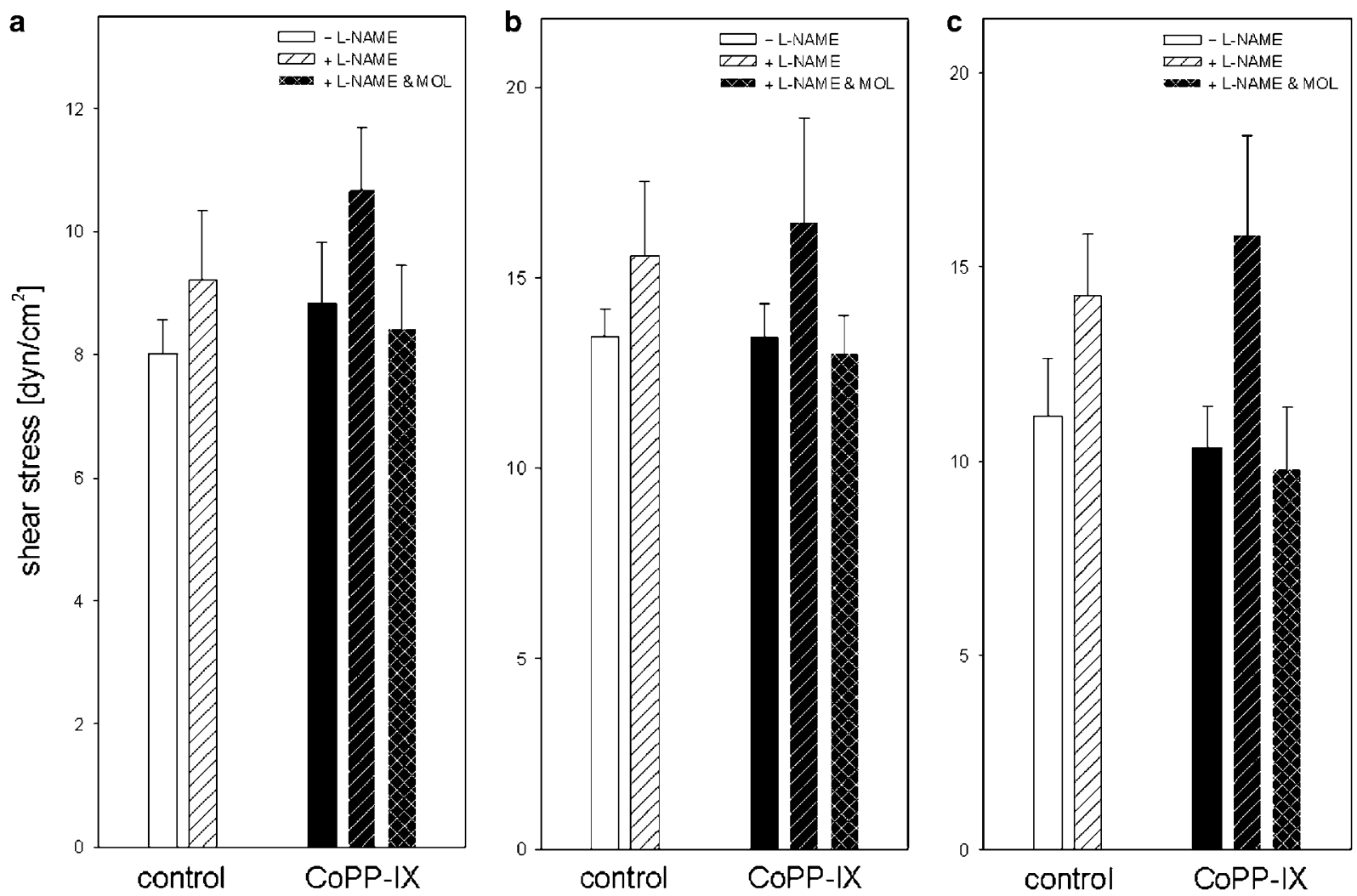

Figure 7 Shear stress $(\tau)$ in terminal afferent vessels (a), sinusoids (b) and postsinusoidal venules (c) of livers, as assessed by in vivo microscopy and calculated according to the following formula: $\tau=4 \eta \mathrm{VQ} / \pi r^{3}$. Mice were either treated with CoPP-IX for HO-1 induction (black bars) or with equivalent volumes of the vehicle $\mathrm{NaHCO}_{3} / \mathrm{PBS}$ (white bars) $24 \mathrm{~h}$ before microscopy. For NOS-blockade additional groups were treated with L-NAME $24 \mathrm{~h}$ before microscopy (hatched bars). To clarify the effect of NOS blockade (L-NAME) with concomitant HO-1 overexpression (CoPP-IX) on the liver microcirculation, recovery of $\mathrm{NO}$ balance was achieved by administration of molsidomine ( $\mathrm{MOL}, 10 \mathrm{mg} / \mathrm{kg}$ bw, i.p.) $24 \mathrm{~h}$ before and immediately after liver resection (chequered bars). Values are means \pm s.e.m.; 5-7 animals per group.

rate, while increasing flow rate did not release NO, implying the contribution of other vasodilators in maintenance of hepatic vascular resistance under high flow conditions. ${ }^{44}$ In support of this, and as observed in the present study, shear stress did not stimulate NOS-2 protein expression however it was capable of inducing HO-1 protein expression. ${ }^{11}$ Thus, it is reasonable to speculate that at least under normal and increased flow conditions in liver microcirculation, $\mathrm{CO}$ rather than NO serves as effective mediator of vasoregulation either via agonism for the sGC or cGMP-independent via activation of vascular smooth muscle $\mathrm{Ca}^{2+}$-activated $\mathrm{K}^{+}$ channels. ${ }^{37,45}$ At the same time, however, there is evidence that $\mathrm{NO}$ availability is mandatory to control vasotonus in case of HO-1 associated hyperperfusion of the liver.

$\mathrm{NO}$ is reported to be released after partial hepatectomy ${ }^{46}$ and seems to be required for adequate liver regeneration inasmuch as NOS-2 deficient mice exhibited impaired regeneration. ${ }^{47}$ In line with this, the increase of proliferative factor activity and c-fos mRNA expression in hepatectomized rats, serving as two indices of the initiation of the liver regeneration cascade, could be inhibited by the NOS antagonist L-NAME, while a NO donor reversed inhibition. ${ }^{10}$ On the contrary, it has been shown that both endogenous NO synthesis and exogenous NO delivery resulted in delayed liver recovery in hepatectomized mice. ${ }^{48}$ The present data provides an explanation to this contradiction in that NO seems not to be mandatory for the liver to sufficiently regenerate upon resection, as far as vasotonic control is adequately maintained by a proportionate $\mathrm{HO}-1$ response. However, in case of HO-1 overexpression, NO is essential to counterbalance hyperperfusion-induced surpassing shear stress and subsequently, shear stress-induced enhancement of proliferation. This has conclusively been shown by the fact that substitution of NO by molsidomine in the CoPP-IX/L-NAME treated animals could reverse the hepatic hyperdynamic condition with super-physiologically accelerated proliferation.

In $\mathrm{HO}-1$ transgenic mice, $\mathrm{CO}$ overproduced through the $\mathrm{HO}$ reaction has recently been shown to interfere with NOmediated vasorelaxing mechanisms. ${ }^{17}$ We now show that the CoPP-IX/L-NAME-treated animals present higher blood flow velocities as well as volumetric blood flow and thus increased shear stress. Moreover, restoration of NO balance by application of molsidomine returned microhemodynamic 
parameters and proliferation capacity of the liver to values of regenerating livers from animals without any pretreatment. Thus, the observed increase of red blood cell velocity and volumetric blood flow in CoPP-IX/L-NAME-treated animals is most likely attributable to the differential modulation of the pre- and intrahepatic vascular system by overabundant $\mathrm{CO}$ and to loss of NO action owing to L-NAME application. The increase of blood volume causes in turn an elevation of shear stress, which consecutively triggers hepatic proliferation. ${ }^{4,5,7}$ At first sight, one might wonder why NO-blockade by L-NAME or HO-1 induction by CoPP-IX alone was without effect and did increase microhemodynamics only in case of NOS-blocked and concomitant HO-1-induced animals. This might be explained by the desensitization of sGC for NO through CO by overexpression of $\mathrm{HO}-1$, as this has been described for HO-1 transgenic mice ${ }^{17}$ as well as the abolishment of NO-mediated attenuation of $\mathrm{CO}$-mediated stimulatory effects on vascular smooth muscle $\mathrm{Ca}^{2+}$-activated $\mathrm{K}^{+}$channels. ${ }^{49}$ In conclusion, our model provides evidence that NO plays a major role in adjusting vascular tone in HO-1 overexpressing animals. This is important in order to maintain adequate perfusion and salutary effect on shear force within the hepatic microvasculature upon liver resection to assure a physiological regeneration process.

\section{ACKNOWLEDGEMENT}

We thank Berit Blendow, Doris Butzlaff, Dorothea Frenz, Maren Nerowski, and Kathrin Sievert (Institute of Experimental Surgery, University of Rostock) for excellent technical assistance and Evelyn Kidess (Institute of Experimental Surgery, University of Rostock) for her expert assistance in editing the manuscript.

Grants: This study is supported in part by a grant of the Deutsche

Forschungsgemeinschaft, Bonn-Bad Godesberg, Germany (Vo 450/7-3).

1. Fausto N. Liver regeneration. J Hepatol 2000;32:19-31.

2. Michalopoulos GK, deFrances MC. Liver regeneration. Science 1997;276:60-66.

3. Taub R. Liver regeneration: from myth to mechanism. Nat Rev Mol Cell Biol 2004;5:836-847.

4. Niiya $T$, Murakami $M$, Aoki $T$, et al. Immediate increase of portal pressure, reflecting sinusoidal shear stress, induced liver regeneration after partial hepatectomy. J Hepatobiliary Pancreat Surg 1999;6:275280.

5. Sato Y, Tsukada K, Hatakeyama K. Role of shear stress and immune responses in liver regeneration after a partial hepatectomy. Surg Today 1999;29:1-9.

6. Thomson RY, Clarke AM. Role of portal blood supply in liver regeneration. Nature 1965;208:392-393.

7. Wang HH, Lautt WW. Evidence of nitric oxide, a flow-dependent factor, being a trigger of liver regeneration in rats. Can J Physiol Pharmacol 1998;76:1072-1079.

8. Busse R, Fleming I. Pulsatile stretch and shear stress: physical stimuli determining the production of endothelium-derived relaxing factors. J Vasc Res 1998;35:73-84.

9. Hirano K, Sato Y, Kobayashi T, et al. Carbon monoxide hemoglobin and bilirubin metabolism in adult living-related liver transplantation. Hepatogastroenterology 2003;50:1745-1748.

10. Schoen JM, Wang HH, Minuk GY, et al. Shear stress-induced nitric oxide release triggers the liver regeneration cascade. Nitric Oxide 2001;5:453-464.

11. Wagner CT, Durante W, Christodoulides N, et al. Hemodynamic forces induce the expression of heme oxygenase in cultured vascular smooth muscle cells. J Clin Invest 1997;100:589-596.
12. Naughton $\mathrm{P}$, Foresti $\mathrm{R}$, Bains $\mathrm{SK}$, et al. Induction of heme oxygenase 1 by nitrosative stress. A role for nitroxyl anion. J Biol Chem 2002;277:40666-40674.

13. Kim YM, Bergonia HA, Muller C, et al. Loss and degradation of enzymebound heme induced by cellular nitric oxide synthesis. J Biol Chem 1995;270:5710-5713.

14. Maulik N, Engelman DT, Watanabe $M$, et al. Nitric oxide-a retrograde messenger for carbon monoxide signaling in ischemic heart. Mol Cell Biochem 1996;157:75-86.

15. Sarady JK, Zuckerbraun BS, Bilban M, et al. Carbon monoxide protection against endotoxic shock involves reciprocal effects on iNOS in the lung and liver. FASEB J 2004;18:854-866.

16. Zuckerbraun BS, Billiar TR, Otterbein SL, et al. Carbon monoxide protects against liver failure through nitric oxide-induced heme oxygenase 1. J Exp Med 2003;198:1707-1716.

17. Imai $\mathrm{T}$, Morita $\mathrm{T}$, Shindo $\mathrm{T}$, et al. Vascular smooth muscle cell-directed overexpression of heme oxygenase-1 elevates blood pressure through attenuation of nitric oxide-induced vasodilation in mice. Circ Res 2001;89:55-62.

18. Pannen BH, Bauer M. Differential regulation of hepatic arterial and portal venous vascular resistance by nitric oxide and carbon monoxide in rats. Life Sci 1998;62:2025-2033.

19. Greene AK, Puder M. Partial hepatectomy in the mouse: technique and perioperative management. J Invest Surg 2003;16:99-102.

20. Feelisch M, Ostrowski J, Noak E. On the mechanism of NO release from sydnonimines. J Cardiovasc Pharmacol 1989;14(Suppl 11):13-22.

21. Yamamoto T, Bing RJ. Nitric oxide donors. Proc Soc Exp Biol Med 2000;225:200-206.

22. Amon $M$, Menger MD, Vollmar B. Heme oxygenase and nitric oxide synthase mediate cooling-associated protection against TNF- $\alpha$ induced microcirculatory dysfunction and apoptotic cell death. FASEB J 2003;17:175-185.

23. Rahman TM, Hodgson $\mathrm{HJ}$. The effects of early and late administration of inhibitors of inducible nitric oxide synthase in a thioacetamideinduced model of acute hepatic failure in the rat. J Hepatol 2003;38:583-590.

24. Osna NA, Haorah J, Krutik VM, et al. Peroxynitrite alters the catalytic activity of rodent liver proteasome in vitro and in vivo. Hepatology 2004;40:574-582.

25. Sass G, Soares MC, Yamashita K, et al. Heme oxygenase-1 and its reaction product, carbon monoxide, prevent inflammation-related apoptotic liver damage in mice. Hepatology 2003;38:909-918.

26. Kountouras J, Boura $\mathrm{P}$, Lygidakis NJ. Liver regeneration after hepatectomy. Hepatogastroenterology 2001;48:556-562.

27. Assy N, Gong $Y$, Zhang M, et al. Use of proliferating cell nuclear antigen as a marker of liver regeneration after partial hepatectomy in rats. J Lab Clin Med 1998;131:251-256.

28. Assy N, Minuk GY. Liver regeneration: methods for monitoring and their applications. J Hepatol 1997;26:945-952.

29. Furnus CC, Inda AM, Andrini LB, et al. Chronobiology of the proliferative events related to angiogenesis in mice liver regeneration after partial hepatectomy. Cell Biol Int 2003;27:383-386.

30. Tarpey MM, Fridovich I. Methods of detection of vascular reactive species: nitric oxide, superoxide, hydrogen peroxide, and peroxynitrite. Circ Res 2001;89:224-236.

31. Richter S, Vollmar B, Mucke I, et al. Hepatic arteriolo-portal venular shunting guarantees maintenance of nutritional microvascular supply in hepatic arterial buffer response of rat livers. J Physiol 2001;531: 193-201.

32. Gross JF, Aroesty J. Mathematical models of capillary flow. A critical review. Biorheology 1972;9:225-264.

33. Hori N, Wiest R, Groszmann RJ. Enhanced release of nitric oxide in response to changes in flow and shear stress in the superior mesenteric arteries of portal hypertensive rats. Hepatology 1998;28:1467-1473.

34. Windberger U, Bartholovitsch A, Plasenzotti R, et al. Whole blood viscosity, plasma viscosity and erythrocyte aggregation in nine mammalian species: reference values and comparison of data. Exp Physiol 2003;88:431-440.

35. Rappaport AM. The microcirculatory hepatic unit. Microvasc Res 1973;6:212-228.

36. Burstyn JN, Yu AE, Dierks EA, et al. Studies of the heme coordination and ligand binding properties of soluble guanylyl cyclase (sGC): 
characterization of $\mathrm{Fe}(\mathrm{II}) \mathrm{sGC}$ and $\mathrm{Fe}(\mathrm{II}) \mathrm{sGC}(\mathrm{CO})$ by electronic absorption and magnetic circular dichroism spectroscopies and failure of CO to activate the enzyme. Biochemistry 1995;34: 5896-5903.

37. Wang R. Resurgence of carbon monoxide: an endogenous gaseous vasorelaxing factor. Can J Physiol Pharmacol 1998;76:1-15.

38. Brune B, Ullrich V. Inhibition of platelet aggregation by carbon monoxide is mediated by activation of guanylate cyclase. Mol Pharmacol 1987;32:497-504.

39. Suematsu M, Goda N, Sano T, et al. Carbon monoxide: an endogenous modulator of sinusoidal tone in the perfused rat liver. J Clin Invest 1995:96:2431-2437.

40. Suematsu M, Kashiwagi S, Sano T, et al. Carbon monoxide as an endogenous modulator of hepatic vascular perfusion. Biochem Biophys Res Commun 1994;205:1333-1337.

41. Sharma VS, Magde D. Activation of soluble guanylate cyclase by carbon monoxide and nitric oxide: a mechanistic model. Methods 1999:19:494-505.

42. Kamiya A, Togawa T. Adaptive regulation of wall shear stress to flow change in the canine carotid artery. Am J Physiol 1980;239:H14-H21.
43. Braet $F$, Shleper $M$, Paizi $M$, et al. Liver sinusoidal endothelial cell modulation upon resection and shear stress in vitro. Comp Hepatol 2004;3:7.

44. Pastor $\mathrm{CM}$, Hadengue A. Shear stress modulates the vascular tone in perfused livers isolated from normal rats. Hepatology 2000;32:786-791.

45. Naik JS, Walker BR. Heme oxygenase-mediated vasodilation involves vascular smooth muscle cell hyperpolarization. Am J Physiol Heart Circ Physiol 2003;285: $\mathrm{H} 220-\mathrm{H} 228$.

46. Hortelano S, Dewez B, Genaro AM, et al. Nitric oxide is released in regenerating liver after partial hepatectomy. Hepatology 1995;21:776-786.

47. Rai RM, Lee FY, Rosen A, et al. Impaired liver regeneration in inducible nitric oxide synthase deficient mice. Proc Natl Acad Sci USA 1998;95:13829-13834.

48. Zeini M, Hortelano S, Traves PG, et al. Assessment of a dual regulatory role for $\mathrm{NO}$ in liver regeneration after partial hepatectomy: protection against apoptosis and retardation of hepatocyte proliferation. FASEB J 2005;19:995-1007.

49. Wu L, Cao K, Lu Y, et al. Different mechanisms underlying the stimulation of $\mathrm{K}(\mathrm{Ca})$ channels by nitric oxide and carbon monoxide. J Clin Invest 2002;110:691-700. 